\title{
A RESISTÊNCIA DO SUJEITO COMPOSITOR/ CANTOR POPULAR DA DÉCADA DE 60
}

\author{
Silvana Carolina Trevizan* \\ Resumo: A década de 60 foi marcada pela explosão de \\ movimentos artístico-culturais promovidos por músicos \\ de uma classe média intelectualizada. Estes movimentos, \\ ligados aos CPCs (Centros Populares de Cultura), tinham \\ por objetivo a conscientização, a politização e, \\ consequentemente, a ascensão da classe proletária. Para \\ tanto, se embasavam em uma teoria específica - a de \\ Cultura Popular - e um de seus focos eram os artistas \\ populares. Entretanto, ao por em prática tais objetivos, \\ terminavam, ainda que inconscientemente, em um \\ discurso de superioridade, quando tentam moldar a \\ cultura e estética musical dos artistas populares. Esta ação \\ ocasiona, por sua vez, um outro discurso de resistência \\ do sujeito artista popular, que não se apropria das ideias, \\ nem tampouco aceita a bossa nova da classe média: a \\ postura desse sujeito materializa-se em seu discurso. A \\ proposta deste estudo é apresentar brevemente o \\ contexto histórico, social e cultural dessa época.
}

Palavras-chave: Sujeito; música; resistência.

\section{A cultura popular: instrumento para conscientização da classe proletária?}

Embasando em leituras de Skidmore, ${ }^{1}$ é possível notar que, a partir do governo Juscelino Kubitschek (1956-1960), evidenciam-se como nunca a esperança e as posteriores desilusões

\footnotetext{
* Universidade Estadual do Oeste do Paraná (Campus de Cascavel).

${ }^{1}$ SKIDMORE, T. Brasil: de Getúlio a Castelo; SKIDMORE, T. Brasil: de Castelo a Tancredo.
} 
de governos que almejavam o rápido desenvolvimento do país e a amenização das desigualdades sociais.

Essa situação irá culminar nas décadas de 50 e 60, as quais marcam o advento da industrialização, racionalização do trabalho, apogeu do sistema capitalista, acarretando, consequentemente, a acentuação das divisões de classes, agravando os problemas sociais e causando instabilidades políticas e econômicas. Insurgem, deste modo, em vários países do globo, releituras do sociólogo alemão Karl Marx, com o intuito de conhecer profundamente as relações sociais, bem como entender as causas de seus conflitos e projetar possíveis amenizações ou até soluções para os mesmos. Assim também ocorre no Brasil, já que este, na condição de terceiro mundo, retrata categoricamente essas tensões.

Assim sendo, as referidas décadas, no Brasil, foram marcadas por explosões artístico-culturais politicamente engajadas promovidas por artistas e intelectuais pertencentes, em quase sua totalidade, a uma classe média. Estes movimentos, ligados aos CPCs (Centros Populares de Cultura), tinham por objetivo a conscientização, a politização e consequentemente, a ascensão da classe proletária.

Uma das faces resultantes dessas novas leituras marxistas, no país foi o conceito de Cultura Popular. Esta seria, portanto, um meio, um conjunto teórico-prático que objetivava a conscientização dos segmentos populares para uma posterior ação política e ascensão da classe proletária. A cultura seria, assim, um instrumento para a promoção da justiça social. ${ }^{2}$ A arte musical, por sua vez, foi um dos instrumentos dessa Cultura Popular.

Estes compositores/cantores entendiam que o "povo" estava alienado dos acontecimentos sociais e políticos, por conta do poder que a elite exercia sobre ele e caberia a eles desmantelar as concepções ingênuas que o povo tinha sobre sua própria realidade.

\footnotetext{
${ }^{2}$ MARTINS. A questão da cultura popular, p. 39.
} 
Como ocorreria esta conscientização por meio da Cultura Popular? Segundo teorias, os revolucionários se apropriariam da cultura do povo, entrariam em contato com ela para conhecê-la e estudá-la para, a partir dela e nela, iniciar o processo de conscientização. Não se tratava de eliminar a cultura do povo, para impor outra conscientizadora, mas, através de uma reforma no interior dela, conscientizar e politizar.

A teoria, observada superficialmente, parece ser viável e revolucionária, contudo possui contradições em si mesma como observa Leite, ${ }^{3}$ pois, ao se reformar a arte do povo, automaticamente, há que negá-la em um primeiro momento, como algo inválido, onde há necessidade de reforma. E ainda afirmar que o povo não possui noção de sua situação de classe e que ele necessita da intervenção da classe intelectualizada e consciente, para abrir seus olhos e assim libertá-lo para poder viver seu livre arbítrio, é antagonicamente negar ao povo o livre arbítrio de querer ou não aceitar ou concordar com os que se supõem esclarecedores.

Chauí, ${ }^{4}$ ao abordar a questão da Cultura Popular, adere à opinião de que esta maneira de encarar a cultura do povo e os procedimentos a serem adotados para a uma suposta desalienação são errôneos e, inclusive, são características de artifícios populistas. Ao concordarmos com o que afirma a autora, admitimos que, ainda que com o intuito de fazer justiça, os militantes estavam, na realidade, repetindo um processo de manipulação das massas, do mesmo modo que fazia a elite.

\section{O compositor/cantor e sua arte de resistir}

No que diz respeito à música engajada do período proposto, o objetivo era fazer da arte musical um meio de reflexão crítica e de protesto à conjuntura político-social que se instaurava.

\footnotetext{
${ }^{3}$ LEITE. Cultura popular: esboço de uma crítica, p. 258.

${ }^{4}$ CHAUÍ. Cultura e democracia, p. 61.
} 
A música de protesto teve início com a bossa nova, estilo musical esteticamente complexo, que misturava heranças da música erudita, do jazz norte-americano, uma "batida renovadora" (introduzida no Brasil por João Gilberto) e uma entonação sutil de voz; porém, em sua gênese, este estilo musical não tinha ainda uma preocupação social. A busca de jovens da classe média por algo novo no âmbito da estética musical, por estarem enfadados do "samba quadrado" (assim chamado pelo grupo) do "morro" (favelas e regiões suburbanas), faz surgir a bossa nova. ${ }^{5}$

Algum tempo depois, ocorre o rompimento da temática intimista conduzido por alguns cantores do meio, como Nara Leão, Carlos Lyra e Sergio Ricardo. A partir de preocupações nacionalistas, apostam em fazer daquela música um manifesto contra as injustiças sociais. Menciona Tinhorão ${ }^{6}$ que, contudo, tais tentativas se apresentavam antagônicas em vários momentos.

Buscavam, por um lado, um denominador comum, uma forma de se abarcarem, na música, classe proletária e classe média para unirem forças e protestarem através da arte e da cultura. Por outro, estigmatizavam as preferências musicais dos artistas do povo. Ao invés de buscarem um caminho para chegar a uma combinação, a um consenso, para, então, haver uma direção político-ideológica e uma possível batalha cultural, sobrepunham, sempre, os costumes, o estilo musical, principalmente no que se refere à estética, da classe média, estigmatizando, assim o samba, por exemplo. Conforme Tinhorão assinala: "Estavam tais jovens de nível universitário nessa preocupação de encontrar uma 'saída' para o samba - que acusavam de 'quadrado', e de, parado em sua evolução, 'só saber falar de morro e barracão'”. ?

\footnotetext{
${ }^{5}$ TINHORÃO. História social da música popular brasileira, p. 310.

${ }^{6}$ TINHORÃO. Pequena história da música popular.

${ }^{7}$ TINHORÃO. História Social da música popular brasileira, p.312.
} 
Surgiam, paralelamente aos CPCs, os Movimentos de Integração "destinados a encontrar uma fórmula de nacionalização e popularização para a bossa nova". ${ }^{8}$ Esses Movimentos eram realizados a partir de reuniões, nas quais artistas dos segmentos populares, como Zé Kéti, Nelson Cavaquinho, Cartola e João do Valle, eram convidados pelos artistas da bossa nova, com o fim de discutirem sobre rumos políticos-sociais do país, comporem músicas, buscando uma troca de ideias sobre esses fatores. Entretanto, afirma Poubel ${ }^{9}$ que as obras dos artistas da classe economicamente desfavorecida estavam sujeitas a adaptações estéticas, conforme a ótica dos artistas da classe média. Neste sentido, defende Leite que "torna-se contraditório oferecer ao povo condições para uma opção política e ao mesmo tempo negar-lhe o arbítrio da criação estética". ${ }^{10}$

Esta situação acarreta o surgimento de uma resistência dos artistas populares às investidas não apenas da elite, detentora dos meios de comunicação e que ditava o que poderia ser considerado como "artisticamente bom", mas sobretudo aos intentos dos artistas da classe média, que subjugavam, de certa forma, a cultura deles. O que melhor comprova essa afirmação é o fato de que a bossa nova, conforme assinala Tinhorão, ${ }^{11}$ não teve aceitação popular. Assim sendo, os artistas pertencentes à classe economicamente desfavorecida não aceitam a imposição estética de uma outra classe economicamente superior à sua. A esse respeito cabe citar De Certeau, quando diz que

A presença e a circulação de uma representação (ensinada como o código da promoção sócio-econômica por pregadores, por educadores ou por vulgarizadores) não indicam de modo algum o que ela é para seus usuários.

\footnotetext{
8 TINHORÃO. Pequena bistória da música popular, p. 234-235.

${ }^{9}$ POUBEL. O nacional, o popular e o democrático na arte de Carlos Lyra.

${ }^{10}$ LEITE. Cultura popular: esboço de uma crítica.

${ }^{11}$ TINHORÃO. História social da música popular brasileira, p. 316.
} 
É ainda necessário analisar a sua manipulação pelos praticantes que não a fabricam. ${ }^{12}$

Analisando a situação dos artistas populares sob o pensamento do historiador citado, compreendemos que nem a cultura da classe média tampouco a cultura da elite determinavam suas ações a ponto de torná-los meros receptores. Eles sabiam qual era sua condição de classe e, em conformidade com ela, tinham seus próprios costumes, cultura e um estilo musical predominante.

Essa resistência que deu valor de sujeitos àqueles artistas está evidente no discurso presente nas canções compostas e executadas pelos mesmos. Na próxima seção, analisaremos uma dessas músicas.

\section{O sujeito cantor/compositor popular: o lugar e a natureza da subjetividade}

Tratando-se de discurso para abordar a resistência e o caráter de sujeito atribuídos aos artistas populares, referenciamos Souza, que a partir de uma abordagem foucaultiana, assevera:

No contexto das práticas de liberdade, o conceito de resistência em Michel Foucault mostra-se assim diretamente ligado ao de subjetivação, na medida em que querer resistir e subjetivar-se remetem a um modo de produção de sujeito cujas relações de força agem tencionando-se, mas nunca obstruindo-se. Este é o próprio da liberdade que abre espaço para a subjetivação e não para o assujeitamento. Se o assujeitamento é um fato historicamente inexorável, não deixar-se assujeitar é resistir, é abrir-se a outros modos de ser sujeito, ainda que desconhecidos. ${ }^{13}$

\footnotetext{
${ }^{12}$ DE CERTEAU. A invenção do cotidiano, p.40.

${ }^{13}$ SOUZA. Resistir, a que será que se resiste? O sujeito feito fora de si, p. 42.
} 
Conforme o autor, a partir da subjetivação, ou seja, da resistência a uma ordem estabelecida, da forma que se encontra de driblar o estabelecido e adaptá-lo segundo a necessidade/desejo do indivíduo é que se constitui o sujeito. Ainda que a situação tencione para a dominação, o sujeito cria dispositivos de resistência em suas práticas. É importante apontar, porém, que o pesquisador assinala a existência de um assujeitamento que é historicamente inflexível, ainda que exista uma força que o confronta, não se deixa assujeitar e resiste, abrindo caminhos e modos de ser sujeito.

Para aclarar esta idéia que nos dá a impressão de ser contraditória, recorremos, novamente, a Souza:

De modo que fazer a experiência de si não significa ir em
busca de um eu genuíno livre de qualquer contaminação
produzido pelo investimento de um regime de poder/
saber. Assim é que foucaultianamente falando, ninguém
é e nem nasce sujeito, seja sob a forma mais libertária, ou
sob o modo mais submetido. Historicamente, não há esse
dia em que um indivíduo lança seu grito de independência
e proclama: de boje em diante serei eu mesmo;
simplesmente porque esse eu mesmo não existe. ${ }^{14}$

Essa impossibilidade da existência de um eu mesmo se dá sob esta concepção, pelo fato de que, ainda que o sujeito possua a possibilidade do deslocamento, da mudança, do inédito, está atrelado a um contexto histórico-social. É um sujeito interpelado pela sua época, ou melhor, pelo discurso de sua época. Ele não pode estar inerte à conjuntura que se estabelece. Ainda conforme Souza: "Certamente a resistência tem um eu como ponto em que e sustenta sua elaboração. Mas este eu é refletido em seu limite exterior.". ${ }^{15}$ Quer dizer, este eu que é a subjetivação do sujeito perante a objetividade, que representa a autonomia do sujeito, é ao mesmo tempo limitado por um exterior, ou seja, pela objetividade.

${ }^{14}$ SOUZA. Resistir, a que será que se resiste? O sujeito feito fora de si, p. 39.

${ }^{15}$ SOUZA. Resistir, a que será que se resiste? O sujeito feito fora de si, p. 41. 
É comum ler e ouvir críticas à posição de Eni Orlandi, precursora da Análise do Discurso pensada por Michel Pêcheux na França e trazida pela mesma ao Brasil, quanto à questão do assujeitamento do sujeito. Entendemos que esse assujeitamento impede qualquer tomada de posição do sujeito. Vejamos o que a autora nos diz:

na relação contínua entre, de um lado, a estrutura, a regra, a estabilização e o acontecimento, e, de outro, o jogo e o movimento, os sentidos e os sujeitos experimentam mundo e linguagem, repetem e se deslocam, permanecem e rompem limites. ${ }^{16}$

Baseando-nos na citação acima e em leituras de outras obras da autora, a conclusão a que chegamos é a de que sua posição condiz com as dos demais autores aqui já referenciados. Quer dizer, há regras, circunstâncias, formações discursivas, horizonte social (como se queira chamar) que submete o indivíduo e o interpela em sujeito; entretanto, existe o lugar do deslocamento (termo utilizado por Eni Orlandi) do sentido e do sujeito que faz com que os sujeitos se diferenciem e que a história se movimente: "E é nesse jogo entre paráfrase e polissemia, ${ }^{17}$ entre o mesmo e o diferente, entre o já-dito e o a se dizer que os sujeitos e os sentidos se movimentam, fazem seus percursos, (se) significam". ${ }^{18}$ Temos, novamente, então, que existem as regras, mas há o espaço para uma subjetividade não-subjetiva.

Para reforçar o referido, recorremos a Pêcheux: "a tomada de posição não é, de modo algum, concebível como um 'ato originário'

\footnotetext{
${ }^{16}$ ORLANDI. Discurso e texto, p. 103.

${ }^{17}$ Segundo Orlandi (Análise de discurso, p.36) a paráfrase ocorre quando no discurso há estabilização do dizer, em que sempre algo se mantém, enquanto que a polissemia dá espaço ao diferente, à criatividade (considerando que essa criatividade estará, ainda, concebida dentro de uma Formação Discursiva, ou seja, um contexto social discursivo)

${ }^{18}$ ORLANDI. Discurso e texto, p. 36.
} 
do sujeito-falante: ela deve, ao contrário, ser compreendida como o efeito, na forma-sujeito". ${ }^{19}$ Assim, o deslocamento do sujeito perante as situações não é originário num processo individual ou biológico. É, na verdade, o efeito de formações discursivas que se constituem e funcionam no sujeito.

Assim, pensamos que tanto Orlandi quanto Pêcheux se posicionam da mesma maneira que Magalhães e Souza ${ }^{20}$ no que diz respeito à vontade de subjetivação do sujeito. A "essência" do sujeito parece-nos ser a mesma para tais autores e, por isso, os intercalamos para a fundamentação deste estudo.

Entendemos, inclusive, que a visão de Possenti, conhecido por fazer crítica ao sujeito assujeitado da Análise do Discurso de orientação francesa, não se difere da mesma, indo ao encontro dos demais estudiosos. Vejamos:

cercado de circunstâncias que certamente não o deixam livre, mas que não o subjugam. O sistema é frouxo, digamos assim, e obriga a escolhas, a uma estética - um estilo, por que não? - da existência. Estamos longe do sujeito assujeitado. ${ }^{21}$

Não conseguimos perceber onde está a diferença dessa concepção de sujeito do discurso para a concepção de Pêcheux ou Orlandi. Mais uma vez, existem as circunstâncias (formações discursivas para Orlandi e Pêcheux) e as regras estão sujeitas ao jogo (deslocamento). Para complementar, seguimos com o autor:

se os sujeitos não inventam o jogo, não significa que não joguem. Além disso, não o fazem todos ou sempre da mesma maneira. Há craques e pernas-de-pau. ${ }^{22}$

\footnotetext{
${ }^{19}$ PÊCHEUX. Semântica e discurso, p. 171-173; itálico do autor.

${ }^{20}$ MAGALHÃES. O sujeito do discurso: um diálogo possível e necessário; SOUZA. Resistir, a que será que se resiste? O sujeito feito fora de si.

${ }^{21}$ POSSENTI. Dez observações sobre a questão do sujeito, p. 32.

${ }^{22}$ POSSENTI. Dez observações sobre a questão do sujeito, p. 29.
} 
Ora, se admitimos que os sujeitos não inventam o jogo, concordamos que o mesmo está pré-determinado, já existe antes dos sujeitos. Assim, não compreendemos por que o autor afirma que o sujeito não é assujeitado, se sua afirmação está tal qual às dos demais teóricos. Não nos importa, porém, discutir esse assunto aqui. Utilizamos este fragmento do texto de Possenti para reforçar nossa posição quanto à existência de um sistema que determina e de uma resistência que promove a mudança.

Também sobre a relação entre subjetividade e objetividade e a constituição de sujeito, Magalhães expõe que

\begin{abstract}
Sendo, nesse sentido, que a materialidade expressa em um discurso traz a marca da subjetividade que a produziu, mas não no sentido de ser apenas expressão da individualidade do autor, pois o que está ali expresso é a relação entre uma individualidade, posta em um tempo e espaço definidos historicamente, e uma realidade que está sendo representada por essa individualidade, com consciência do que está fazendo, mas sem o domínio de todas as alternativas postas por essa mesma realidade. ${ }^{23}$
\end{abstract}

Sob uma leitura de Lukács acerca da subjetividade marxista, a autora reafirma a existência de um sujeito regido tanto pela subjetividade quanto pela materialidade. Está subordinado a esta, pois está inserido em um tempo e espaço na história. Não há como existir um sujeito que esteja fora de órbita de sua conjuntura histórico-social. A liberdade de escolha que lhe é possibilitada no emaranhar dessas tensões históricas e sociais, mesmo que também pré-estabelecidas, são o espaço que o eu sujeito reclama, resultando na subjetividade, a qual é a mola propulsora para que o inédito e o único ocorram.

${ }^{23}$ MAGALHÃES. O sujeito do discurso: um diálogo possível e necessário, p. 76. 


\title{
4. Uma questão de opinião
}

Realizaremos, agora, uma análise do discurso da música Opinião, composta em 1964 por Zé Kéti, cantor e compositor carioca, pertencente aos segmentos populares, famoso por compor sambas e por ter se integrado ao grupo $A$ voz do morro na década de $60:^{24}$

\author{
Podem me prender \\ Podem me bater \\ Podem, até deixar-me sem comer \\ Que eu não mudo de opinião \\ Daqui do morro \\ Eu não saio, não \\ Se não tem água \\ Eu furo um poço \\ Se não tem carne \\ Eu compro um osso \\ E ponho na sopa \\ E deixa andar \\ Fale de mim quem quiser falar \\ Aqui eu não pago aluguel \\ Se eu morrer amanhã, seu doutor \\ Estou pertinho do céu
}

A canção acima transcrita evidencia um sujeito que resiste às idéias e práticas dos artistas da classe média, de duas maneiras: com relação à estética musical que queriam estabelecer, já que a música está gravada sob o gênero samba e não bossa nova e, inclusive, foi assim interpretada pelo cantor no Show Opinião, em 1964, quando se apresentaram, no mesmo palco Nara Leão (representante da classe média intelectualizada), Zé Kéti (representando o morro do Rio de Janeiro) e João do Valle

\footnotetext{
${ }^{24}$ Informações extraídas do site do Dicionário Cravo Albin de Música Popular Brasileira (http://www.dicionariompb.com.br/ze-keti/dados-artisticos).
} 
(representando o sertão do norte do Brasil), ${ }^{25}$ com o intuito de parecer que aquela mescla de classes, estilo e estética acontecia na história musical brasileira, quando na realidade, como expõe Tinhorão, ${ }^{26}$ resultou em algo muito artificial. De Certeau supõe que "os usuários façam uma bricolagem com e na economia cultural dominante, usando inúmeras e infinitesimais metamorfoses da lei, segundo seus interesses próprios e suas próprias regras". ${ }^{27}$ A idéia do autor está de acordo com o ocorrido no fato exposto no parágrafo anterior, visto que, além de não acatarem o ritmo samba para a canção, utilizaram-se de um espetáculo agenciado pelos artistas cepecistas para divulgarem sua arte.

A outra forma de resistência consiste, por meio da materialidade discursiva, na voz de um sujeito que, claramente, marca sua subjetividade, sua escolha perante sua realidade. Há um interlocutor ("Seu doutor"), quer dizer, alguém que se presume apresentar alguma titulação acadêmica, alguém economicamente melhor estabelecido que o sujeito que profere o discurso e com o qual há um embate, pode-se dizer até agressivo. Os cinco primeiros versos silenciam uma pressão por parte de alguém que insistia que o mesmo abandonasse o morro, lugar que defende e insiste em ficar, apesar das adversidades que enfrenta e faz valer o pensamento de De Certeau de que "[o] cotidiano se inventa com mil maneiras de caça não autorizada" ${ }^{28}$ Há um sujeito que resiste aos problemas, criando alternativas para solucioná-los ou amenizá-los, utilizando, inclusive, de práticas subversivas, como não pagar aluguel, por exemplo. Ele resiste à opinião de um "doutor", que quer fazê-lo mudar de opinião, argumentando, inclusive, os motivos pelos quais prefere ficar ali (cf. três últimas linhas).

\footnotetext{
${ }^{25}$ Sobre definições de Morro e Sertão aqui, ver o ensaio histórico de Marcos Napolitano (A canção engajada no Brasil: entre a modernização capitalista e o autoritarismo militar (1960-1968)).

${ }^{26}$ TINHORÃO. História social da música popular brasileira.

${ }^{27}$ DE CERTEAU. A invenção do cotidiano, p. 40.

${ }^{28}$ DE CERTEAU. A invenção do cotidiano, p. 38.
} 


\section{Considerações finais}

Neste estudo, tivemos a intenção de demonstrar a resistência que os artistas pertencentes aos segmentos populares na década de 60 apresentavam perante uma tentativa de homogeneização artístico-cultural que artistas da classe média, empolgados com o estilo bossa nova e com a promoção da ascensão sócio-cultural da classe proletária a partir da música, tentaram promover.

Os CPCs tinham uma orientação advinda do neomarxismo que se disseminava na América Latina. Segundo o sociólogo alemão Marx, as transformações de ordem social só seriam possíveis se fossem pela

criação das próprias massas trabalhadoras, com o proletariado à frente. Ou seja, se surgisse do movimento histórico real de que participa o proletário na condição de classe objetivamente portadora dos interesses mais revolucionários da sociedade. ${ }^{29}$

Essa concepção coloca, pois, em evidência a classe trabalhadora e a entende como protagonista das mudanças políticas, econômicas, sociais e culturais. Entretanto, na questão aqui examinada, a vontade de mudança, ou melhor, o motor que tentava promover a mudança não estava na classe proletária e sim na classe média. Não estava nos artistas economicamente desfavorecidos, mas nos artistas da bossa nova. As investidas não partiram de uma organização e de uma essência popular, e sim de um grupo que tentou, ainda que inconscientemente, impor sua cultura para "mudar" uma massa com a qual entendiam que precisavam contar para mudar a conjuntura social. O objetivo não foi atingido e resultou na resistência daqueles que não aceitaram abnegar sua cultura.

${ }^{29}$ MARX. O capital, p. 12. 
Tais artistas tentaram forçar uma estética musical e buscaram conscientizar à população a partir da música e, para tanto, partindo dos artistas populares. Porém, ao contrário do que acreditavam os artistas da bossa nova, os artistas populares sabiam de sua realidade e interpretavam-na de sua forma, conforme apresentamos na canção analisada.

Ainda que os referidos artistas não fossem detentores de conhecimento científico e acadêmico, não estivessem por dentro das idéias marxistas de dominação, ideologia, luta de classes, e não possuíssem, talvez, o mesmo conhecimento aprofundado sobre estética musical, não ignoravam as injustiças que ocorriam, mas interpretavam-nas de sua forma, do lugar em que se encontravam. Aponta Magalhães que

A subjetividade que percebe carências precisa conhecer a legalidade da objetividade para nela interferir, mas apenas dentro das possibilidades permitidas por essa mesma objetividade e, efetivamente, com o nível de conhecimento que essa subjetividade, que é individual e histórica, possui. $^{30}$

Desta forma, dentro das possibilidades que a materialidade permitia, o sujeito artista popular fez notar sua subjetividade. É inútil tentar forjar uma realidade. $\mathrm{O}$ discurso do sujeito será inevitavelmente fiel ao espaço histórico e social que ocupa, pois mesmo a subjetividade, conforme Magalhães, é individual, mas também histórica.

Arriscamos, então, em sugerir que, se os artistas em questão não reagiam conforme o esperado pelos Bossa-Novas àquela situação que tentavam reverter, era, não pela falta de consciência de sua situação enquanto grupo social, mas pela falta de esperança e/ou gana para entrar em conflito com a classe dominante e tentar reverter tal situação, até porque estavam

${ }^{30}$ MAGALHÃES. O sujeito do discurso: um diálogo possível e necessário, p. 78. 
encabeçados e subordinados à diretrizes de outra classe, a qual almejava o poder e, também, porque, apesar das adversidades enfrentadas pela dificuldade financeira, que é ocasionada pela injustiça social, eles, de sua maneira, resistiam. De Certeau atenta para o fato de que:

A uma produção racionalizada, expansionista além de
centralizada, barulhenta e espetacular, corresponde outra
produção, qualificada de consumo: esta é astuciosa, é
dispersa, mas ao mesmo tempo ela se insinua ubiquamente,
silenciosa e quase invisível, pois não se faz notar com
produtos próprios mas nas maneiras de empregar os
produtos impostos por uma ordem econômica
dominante. $^{31}$

Assim, se não tiver água, fura-se um poço; se não houver carne, dá-se um jeito e compra-se osso para fazer sopa; se não se tiver casa própria registrada, também não se paga aluguel e podese, inclusive, ter uma vista privilegiada do mar, em algumas das favelas do Rio de Janeiro. E pode-se, inclusive, não aderir à bossa nova e utilizar-se dos meios midiáticos produzidos pelos artistas da classe média para cantar o samba.

Não estamos aqui supondo que a ordem estabelecida pela classe dominante é justa, tampouco que deva ser aceita. O que quisemos evidenciar é que, onde à primeira vista existe apenas passividade, por um olhar mais sensível e crítico é possível perceber também resistência, ainda que silenciosa ou, se não se pode dizer silenciosa, com menor poder de atingir a sociedade como um todo, pela própria situação desprivilegiada em que os artistas se encontravam na ordem do discurso.

${ }^{31}$ DE CERTEAU. A invenção do cotidiano, p. 39. 
Resumen: Los años 60 estuvieron marcados por la explosión del movimiento artístico y cultural promovido por músicos de una clase media intelectualizada. Estos movimientos eran vinculados a los CPCs (Centros de Cultura Popular), tenían como objetivo la movilización, politización y, por consiguiente, el aumento de la clase proletaria. Para esto, tenían por base una teoría específica - la de Cultura Popular - y uno de sus focos fueron los artistas populares. Sin embargo, cuando ponían en práctica estos objetivos, aunque sea inconscientemente, demostravan tener un discurso de superioridad, cuando tratavan de dar forma a la cultura y a la estética musical de los artistas populares. Esta acción resulta, a su vez, en un otro discurso de resistencia del sujeto artista popular, que no se apropia de las ideas y no acepta la "bossa nova" de la clase media: la postura de este sujeto se materializa en su discurso. El propósito de este estudio es presentar brevemente el contexto histórico, social y cultural de esa época

Palabras-clave: Sujeto; música; resistencia.

\section{Referências}

ALBIN, R. C. Dicionário Cravo Albin da música popular brasileira. Rio de Janeiro, 2002-2011. Disponível em: < http://www.dicionariompb. com.br>. Acesso em: 4 abr. 2011.

CHAUÍ, M. Cultura e democracia: o discurso competente e outras falas. São Paulo: Ed. da Unicamp, 1981.

DE CERTEAU, M. A invenção do cotidiano: as artes do fazer. 5. ed. Trad. Ephaim Ferreira Alves. Petrópolis: Vozes, 1996.

LEITE, S. U. Cultura popular: esboço de uma crítica. In: FÁVERO, O. (Org.). Cultura popular e educação popular: memória dos anos 60. Rio de Janeiro: Graal, 1983.

MAGALHÃES, B. O sujeito do discurso: um diálogo possível e necessário. Linguagem em Dis(curso), Tubarão, v. 3, n. especial, p. 73-90, 2003. 
MARTINS, C. E. A questão da cultura popular. In: FÁVERO, O. (Org.). Cultura popular e educação popular: memória dos anos 60. Rio de Janeiro: Graal, 1983.

MARX, K. O capital: crítica da economia política. São Paulo: Nova Cultural, 1996.

NAPOLITANO, M. A canção engajada no Brasil: entre a modernização capitalista e o autoritarismo militar (1960-1968). Ciência Hoje, Rio de Janeiro, v. 24, n. 141, p. 34-41, 1998.

ORLANDI, E. P. Discurso e texto: formação e circulação dos sentidos. Campinas: Pontes, 2001.

ORLANDI, E. P. Análise de discurso: princípios e procedimentos. 6. ed. Campinas: Pontes, 2006.

PECHÊUX, M. Semântica e discurso: uma crítica à afirmação do óbvio. Trad. Eni Orlandi [et al].Campinas: Ed. da Unicamp, 1997.

POSSENTI, S. Dez observações sobre a questão do sujeito. Linguagem em Dis(curso), Tubarão, v. 3, n. especial, p. 27-35, 2003.

POUBEL, M. L. O nacional, o popular e o democrático na arte de Carlos Lyra. A Nova Democracia, Rio de Janeiro, ano II, n. 14, 2003. Disponível em: < http:/www.anovademocracia.com.br/no-14/967-onacional-o-popular-e-o-democratico-na-arte-de-carlos-lyra $>$. Acesso em: 4 abr. 2011.

SKIDMORE, T. Brasil: de Getúlio a Castelo. Rio de Janeiro: Saga, 1969.

SKIDMORE, T. Brasil: de Castelo a Tancredo. 6. ed. São Paulo: Paz e Terra, 1988.

SOUZA, P. Resistir, a que será que se resiste? O sujeito feito fora de si. Linguagem em Dis(curso), Tubarão, v. 3, n. especial, p. 37-54, 2003.

TINHORÃO, J. R. Pequena história da música popular: da modinha à canção de protesto. Petrópolis: Vozes: 1974.

TINHORÃO, J. R. História social da música popular brasileira. São Paulo: Ed. 34, 1998.

Recebido para publicação em 4 de abril de 2011 Aprovado em 30 de junho de 2011 